\title{
Avaliação e novas perspectivas de aprendizagem em História.
}

Marisa Noda

\section{RESUM0}

Pretende-se discutir neste artigo os tipos de avaliação para a disciplina de História do Ensino Fundamental e Médio. A avaliação é entendida como parte do processo,em que os alunos construem seu próprio conhecimento histórico, a partir de procedimentos desenvolvidos pelo professor em sala de aula. Ponto que também merecerá atenção é o significado do planejamento para que uma avaliação comprometida com a aprendizagem se realize.

Palavras-chaves: planejamento, avaliação, metodologias do ensino de história e aprendizagem em história.

"A formação dos nossos jovens não poder ser deixada aos azares da inspiração do momento. (PROENÇA, 1992, p. 173)

Este texto deriva do curso 'Avaliação e Novas Perspectivas de Aprendizagem em História' ministrado no IV Simpósio do Laboratório de Ensino de História, e, não só tem como objetivo principal, discutir a avaliação no ensino de história e como também as perspectivas de aprendizagem. As colocações aqui feitas, partem de leituras, discussões e troca de experiências realizadas durante os anos de atuação como professora da rede pública de ensino, que resultaram de práticas em sala de aula, experiências que representaram necessariamente novas pesquisas, outros debates, tinhanhas entre colegas, e, sucessivamente, o repensar do cotidiano escolar.

Considerando conforme Monteiro que "avaliação é o processo que

\footnotetext{
1 Professora de História do Ensino Fundamental e Médio da Rede Estadual de Ensino do Estado do Paraná e de Prática de Ensono de História da Faculdade Estadual de Filosofia Ciências e Letras de Jacarezinho. Mestre em História Social pela Universidade Estadual de Maringá.
} 
permite reconbecer se os objetivos educacionais que previamente definiu foram ou não atingidos pelos alunos" (2001, p.119), e, como Proença que: "a avaliação é, pois, um instrumento indispensável num processo de ensino/aprendizagem que tenha como finalidade facilitar o progresso escolar" (p.144), deve-se refletir o significado do planejamento e da construção do processo ensino aprendizagem e ainda suas implicações os quais será necessários para entendermos a avaliação.

No sistema de ensino brasileiro, a avaliação é tradicional, sendo um dos deveres a serem cumpridos tanto pelos professores como pelos alunos durante 0 ano letivo, ou no final de cada bimestre, como é o mais comum. E como quase sempre, avaliar representa uma obrigação, um dever a mais a ser realizado, acaba sendo um mecanismo sem fundamento, sem valor, - apesar do valor, nota que lhe é atribuída - perde sua contribuição maior que édemostrar se os objetivos propostos foram alcançados:

0 papel atribuído em qualquer sistema de ensino está necessariamente relacionado com as finalidades e objetivos do próprio sistema. É através da avaliação que 0 professor se vai apercebendo até que ponto os objetivos vão sendo atingidos.(PROENÇA, 1992, p. 143)

Traçar objetivos, pressupõe um planejar por parte do professor. 0 planejamento nutri-se de reflexão acerca dos conteúdos; dos conceitos; do cotidiano da sala de aula; da contribuição que cada aluno poderá oferecer, contribuição que pode ser fruto de um conhecimento formalizado ou das dificuldades de cada um dos envolvidos no processo; dos acontecimentos do período em que se está vivenciando; enfim, significa uma visão global de todos os agentes que interferem e influenciam no processo de construção do conhecimento, como enfatiza a professora Maria Cândida Proença:

Ao planear o ensino o professor tem também de ter em conta os problemas sociais do nosso tempo de forma a sensibilizar os alunos para sua solução. Se os conteúdos programáticos do $9^{\circ}$ ou $11^{\circ}$ anos se prestam indiscutivelmente para orientar o ensino segundo esta visão, o professor não deve, contudo, deixar de aproveitar as oportunidades para, através do estudo de outras épocas, preparar o terreno para a sensibilização dos alunos aos problemas do seu tempo. (PROENÇA, 1992, p. 175) 
0 professor de História, ao planejar, tem de estar atento a muitos aspectos que são formadores dos fundamentos de sua disciplina, e uma delas é entender que sua opção filosófica e pedagógica norteará o desenvolvimento de seus objetivos, desta forma, como serão estes alcançados, dependerá da metodologia de ensino aplicada, e que esta, por sua vez, também é resultado da preferência do professor por uma escola histórica, a qual é preponderante na forma de avaliação.

A estas, somam-se outras questões que são importantes quando se planeja, como retrata Proença: "Donde se parte? Para quê levar a cabo este trabalho?, Que assunto se vai estudar? Como é que vai se realizar o trabalho? Para quem é que se vai organizar? Com que recursos se pode contar?" (1992, p.173), além de, como pensamos a escola? Qual é sua função? Ao fazer estes questionamentos contribui-se para conhecer as condições em que se vai trabalhar, e principalmente, com quem se vai desenvolver o trabalho, e quem é o aluno. Entender de onde o outro parte é essencial no trabalho do professor.

Através destes entendimentos sobre o planejamento pode-se caminhar no sentido da construção do conhecimento histórico de forma sistêmica, com base sólida, como toda construção deve ser, para poder representar reflexão, deixando espaço para a criatividade e os interesses dos alunos, transformandoo em sujeito emancipado como argumenta Paulo Freire, e responsável pelo espaços sociais dos quais participa.

Monteiro ao afirmar que "é fundamental que se estabeleça uma clara sintonia entre o ensino, a aprendizagem e a avaliação praticada, que é a resultante de um conjunto de etapas incluidas no processo educacional" (2001, p.119), alerta que há um processo, e que nele a avaliação não é separada, nem a sua última etapa, mas, uma fornecedora de pistas para o professor, a partir dela confirma-se, ou não, se o caminho para alcançar os objetivos está sendo construído, e quais os conhecimentos que ele necessita nesta construção, e ainda, por último, de que forma a metodologia escolhida está auxiliando no trabalho.

È prioridade também destacar:

A principal ênfase na avaliação reside na extensão até onde as metas educacionais são alcançadas, por isso ela é, fundamentalmente, descritiva e informativa. Descreve qual é a situação do aluno num determinado momento; compara com 
o que devia ser, isto é, a situação que se desejaria face aos objetivos enunciados; identifica as discrepâncias existentes. A informação resultante deste processo permite ao professor procurar as causas das discrêpancias encontradas e propor soluções, introduzindo estratégias alternativas no seu trabalho e no do aluno. (PROENÇA, 1992, p. 144)

Diante deste esclarecimento acerca da avaliação estabelece-se que 0 trabalho do professor é exatamente encontrar métodos para serem trabalhados em determinados conteúdos ou conceitos dentro da gama de fundamentos que regem o ensino da disciplina, a avaliação estaria insuflando novas perspectivas de aprendizagem em história.

Com relação aos tipos de avaliação que estão sendo utilizados no ensino de História, e também em outras disciplinas do currículo, é importante se ter claro quando e como usá-las de forma coerente com as premissas e os objetivos estabelecidos no planejamento. É necessário um conhecimento de cada um deles e utilizá-los em momentos diferentes do processo de ensino, entendendoos como auxiliares das observações que se faz no dia-a-dia do aluno, aquela que depende do olhar do professor, do perceber o outro, que no caso é o aluno, nos detalhes cotidianos.

Nesta observação que se faz no cotidiano durante as aulas, o professor deve estar atento a aspectos que se denominará subjetivos, pois estão, ou não presentes, na maioria das vezes, no comportamento do aluno ao enfrentar os problemas que devem ser resolvidos para que ele consiga caminhar à aquisição de conhecimentos.

Estes aspectos são apresentados por Maria Cândida Proença, dentro do que ela chama de listas de verificação de participação na aula, atitude de cooperação na aula, noção de responsabilidades, relação com o professor. Dentro destas listas o professor deve observar atividades como:

se 0 aluno tira conclusões precipitadas, faz perguntas que revelam não ter estado com atenção na aula, é indiferente à contribuição dos outros, tem medo de cometer erros, está ansioso para participar, escuta atentamente, toma notas, mostra grande interesse pelo assunto, está freqüentemente a desenhar ou olhar para a rua, entrega os trabalhos a tempo, desiste com facilidade, não liga 
importância às sugestões, mostra falta de respeito pelo professor, depende demasiado da ajuda do professor, dificulta a tarefa do professor pela sua atuação como líder de grupo, entre outras. ( PROENÇA, 1992, p. 166-167)

Diante da responsabilidade que exercer a profissão representa e das muitas tarefas, principalmente, das chamadas obrigações burocráticas, que tomam uma grande parte do tempo do professor, como montar listas verificando todos estes itens? Seria uma tarefa a mais para o professor já tão judiado pelas longas jornadas de trabalho, sem falar das salas lotadas, alunos indisciplinados, carentes de atenção, carentes de alimentação, carentes de formação, e muitas outras carências.

Primeiramente, foram colocados como pontos a serem observados e não simplesmente anotados. Segundo, estas observações devem sempre ser explicitadas pelo professor, não para agredir ou ameaçar, mas para que os alunos percebam que estão sendo observados e quando os alunos percebem que são notados por seus professores, que suas deficiências e esforços são apreciados, há um momento de aproximação entre professor e aluno, pois por mais que as crianças e jovens estejam embrutecidos pelas carências materiais e afetivas, é natural nestes, a necessidade de se fazerem notar. Assim, a experiência tem mostrado que avaliar significa também aproximar-se, comprometer-se.

\section{Avaliação diagnóstica e avaliação formativa no ensino de história}

É costumeiro realizar a avaliação diagnóstica no início de qualquer tipo de trabalho, seja aquele planejado para uma unidade, bimestre ou do ano letivo, para se ter uma visão geral de como os alunos estão frente a determinados conhecimentos, ou quais são seus interesses e aptidões (PROENÇA, 1992, p.119). Este tipo de avaliação deve ser elaborada com extremo cuidado, para que, através dela, o professor possa reconhecer se os requisitos que serão necessários para atingir os objetivos aos quais se quer alcançar, foram apropriados pelos alunos .

A avaliação diagnóstica também pode ser utilizada durante os trabalhos, quando o aluno não consegue avançar em direção aos objetivos determinados. Para este fim, é essencial que seja montada de forma que leve o professor a conhecer as origens das dificuldades vividas pelo aluno, e não novamente no 
sentido de confirmá-las. É necessário ficar atento para perceber que outros problemas, não só os ligados diretamente à aprendizagem de História, podem interferir na construção do conhecimento pelos alunos, como por exemplo, a metodologia utilizada pelo professor, pode não estar sendo adequada para aquele conteúdo, ou que o problema pode estar em como a criança ou adolescente compreende a história.

Neste tipo de avaliação, pode-se proceder de diferentes modos a fim de se obter as informações acerca da aprendizagem dos conteúdos e atitudes: teste escrito, trabalho em grupo, ou questionamentos orais para todo o grupo. Dentre os três tipos, o professor deve ficar atento em alguns itens da lista de verificação sugerida acima, como por exemplo: se o aluno tira conclusões precipitadas, é indiferente à contribuição dos outros, tem medo de cometer erros, está ansioso para participar, escuta atentamente, mostra grande interesse pelo assunto, desiste com facilidade, não dá importância as sugestões, depende demasiado da ajuda do professor, pois serão estas observações que ajudarão na elaboração do perfil do aluno. Quando o professor conhece seu aluno, ele obtém dados para a ação educativa do mesmo.

A avaliação formativa é utilizada quando os trabalhos estão iniciados, ou seja, quando o professor já explicitou seus objetivos e a metodologia escolhida, a prática já está em andamento. Sua função formativa se faz porque:

parte dos objectivos selecionados, aplica-se durante 0 processo de ensino aprendizagem, fornece informações sobre as estratégias escolhidas pelo professor, permite ao aluno o conhecimento do seu rendimento escolar e serve para o aluno reforçar os seus conhecimentos e competências. (MONTEIR0, 2001, p. 121)

Ao ser utilizada, é necessário seguir algumas etapas:

Recolha de informações que dizem respeito aos progressos e dificuldades encontrados pelo aluno na aprendizagem. Interpretação destas informações numa perspectiva de referência criterial, e, na medida do possível, deteç̧ão dos fatores que estarão na origem destas dificuldades. Adaptação das atividades de ensino/ aprendizagem em função da interpretação das informações recolhidas. (PROENÇA, 1992, p. 151). 
Quando a avaliação dá a oportunidade de conhecer as dificuldades dos alunos, interpretar as origens destas dificuldades e adaptar as atividades didáticas para que os resultados obtidos sejam os mais próximos possíveis dos objetivos propostos, pode-se considerá-lo sem dúvida, como parte integrante do processo ensino aprendizagem, e não um fim em si mesmo, pois ele permite ao professor e ao aluno, como lembram SCHMIDT e CAINELLI a obtenção dos resultados $e$ as causas dos insucessos na aprendizagem (2004, p148).

Embora amplamente criticada, a avaliação no ensino de História tem valorizado muito a memorização; que pressupõe também uma atribuição de notas e uma classificação. Encerrando aí o processo de ensino / aprendizagem, exatamente no momento em que deveria começar, ou pelo menos prosseguir. Para findar esta prática tão comum é importante estabelecer algumas mudanças na maneira de entender a avaliação, não como una, mas como práticas diárias, que devem estar presentes nas várias atividades propostas pelo professor e nas várias metodologias de ensino.

Entre as diversas metodologias possíveis no ensino de História, a metodologia da investigação é bastante propícia, pois ela não despreza o conhecimento trazido pelo aluno: ao serem relevadas as concepções dos alunos, os erros não devem ser objetos de punições, mas pontos de partida para a elaboração de conhecimento mais complexos. (SCHMIDT e GARCIA, 2003, p. 228).

Ao se utilizar do método de investigação, o professor deve esclarecer que a história que recebemos foi produzida a partir de leituras de determinadas fontes. E, ao trabalhar com estudos de fontes em sala de aula, o professor proporciona ao aluno aprender história com os mesmos instrumentos com os historiadores a constrói.

Como esclarecem Maria Auxiliadora Schmidt e Tânia Braga Garcia o uso do método de investigação nas aulas de História seria "a recuperação da bistoricidade do método da História" (2003, p. 229). Outro ponto salientado pelas professoras é o de que:

como afirma Prats o ensino de História requer introduzir o aluno no método histórico, cujos elementos principais que deverão estar presentes em todo o processo didático, são: aprender a formular hipóteses; aprender a classificar e analisar as fontes; aprender a analisar a credibilidade das fontes históricas; aprender relações de causalidade e a construir a explicação histórica ( SCHMIDT e GARCIA, p. 2003, p. 203). 
Cada um destes passos apontados pelas historiadoras requer práticas avaliativas por parte do professor, sempre tendo em vista o papel ativo que 0 aluno tem nesta metodologia de trabalho. E que cada passo do processo didático requer estar atento em como o aluno está construindo seu saber, a utilização das atividades da lista de verificação, já citada acima, pode fundamentar a observação do professor.

0 método investigativo favorece as práticas avaliativas, na medida em que coloca o aluno em situações variadas de aprendizagem, além de desenvolver sua autonomia e criatividade crítica (SCHMIDT e GARCIA, 2003, p. 227), propicia ao professor poder assisti-lo em diferentes momentos da produção do conhecimento e envolto em problemáticas diversificadas, sejam elas de categoria cognitivas ou atitudinais. Estes momentos distintos, significam a possibilidade de avaliar o caminho que o estudante percorre para modificar seu pensamento frente a determinado conteúdo histórico.

0 trabalho com o método investigativo carrega um diferencial significativo na relação de poder em sala de aula, traz consigo "uma concepção de ensino aprendizagem onde o aluno tem um papel ativo e o professor a função de mediador" (SCHMIDT e GARCIA, 2003, p.229), isto caracteriza que o ensino/ aprendizagem vai além do conceito (ou pré-conceito) que o 'professor ensina, porque só ele tem o conhecimento, e o aluno aprende passivamente', e, se há mudança nesta perspectiva, há mudança também na perspectiva da avaliação, que não se dará somente em cima do que o aluno aprendeu, mas sim, em como desenvolveu, construiu seu conhecimento.

0 método de investigação histórica foi aqui explorado de forma bastante inicial, apenas com o intuito de discutir com o professor que a forma como ele avalia está diretamente ligado ao seu método de ensino, à maneira de como concebe sua disciplina. Mas, é imprescindível citar que, quando a investigação chega às aulas de História no Ensino Fundamental e Médio proporciona ao aluno entender que o conhecimento histórico pode ser produzido a partir de sua realidade.

Maria Auxiliadora Schmidt e Tânia Braga Garcia alertam que a consciência histórica, que tem como função específica ajudar a compreender a realidade passada para compreender a realidade presente (2003, p. 235), e se, a construção desta consciência histórica se faz, em grande parte 
dentro das aulas de História, o professor deve estar atento, pois ao considerar a avaliação como o fim do processo ensino/aprendizagem, compromete a construção desta consciência, na medida em que esta ficaria à mercê de influencias vindas de outros pontos, como por exemplo os meios de comunicação, que nem sempre trazem uma visão livre de preconceitos.

No ensino de História, enquanto a avaliação for entendida como integrante de uma prática metodológica que busque significado no saber que se constrói em sala de aula, pode-se afirmar que as crianças estarão sendo preparadas, munidas de um conhecimento, para enfrentar o mundo como nos aponta Hanna Arendt, quando discute a crise na educação.

\section{Referências}

ARENDT, H. Entre o Passado e o Futuro. São Paulo: Perspectivas. 1972.

CARDOSO, 0. P. Representações dos professores sobre saber histórico escolar. História e Ensino, Londrina, 2004, vol. 10, 2004. p. 53-63.

FONSECA, S. G. Didática e Prática de Ensino de História. Campinas: Papirus, 2003.

MONTEIR0, M. C. Didáctica da História teorização e prática - algumas reflexões. Lisboa: Plátano, 2001.

PROENÇA, M. C. Didáctica da História. Braga: Universidade do Minho,1992.

SCHMIDT, M. A.; GARCIA, T. B. 0 trabalho histórico em sala de aula. História e Ensino, Londrina, vol 9, p. 223-241.

SCHMIDT, M. A.; CAINELLI, M. R. Ensinar História. São Paulo: Scipione, 2004. 


\section{The evaluation and new perspectives of learning in history.}

\section{ABSTRACT}

It intends itself to discuss in this article the types of the evaluation to the discipline of History of the Fundamental and Medium teaching and the perspectives that then can appear with relation at learning. The evaluation is understood as part of the process has in view that students build your own historical knowledge starting from procedures developed by teacher in classroon. Paint that will also deserves attention is the meaning of the equal planning in order to the compromised evalution with the learning takes place.

Keys-words: planning, evaluation, methodolgies of the teaching of History and learning in history. 